\title{
Alcaptonuria with Myelopathy and Neuropathy
}

\author{
Milica Mavra ${ }^{a}$ Geeti Chadha ${ }^{a}$ Moheb M. Henein ${ }^{a}$ \\ Sneha Bhargava ${ }^{b}$ \\ aDepartment of Medicine, Neurology Unit, and ${ }^{\mathrm{b}}$ Department of Radiology, \\ Mubarak Al Kabeer Hospital, Kuwait
}

\section{Key Words}

Alcaptonuria $\cdot$ Myelopathy $\cdot$ Neuropathy

\begin{abstract}
Objective and Importance: Myelopathy secondary to alcaptonuria or ochronosis has been reported in only a few patients, but no reports on alcaptonuria and neuropathy have been available. Clinical Presentation: We report a case of alcaptonuria in a 55-year-old patient who presented with neuropathy and myelopathy after sustaining injuries in a traffic accident. Alcaptonuria, which is a rare autosomal recessive disorder characterized by the inability to metabolize homogentisic acid, was confirmed by the presence of homogentisic acid in the urine of the patient and by typical radiological changes in the spine, hips and knees. Conclusion: The association of alcaptonuria and peripheral neuropathy in this patient may remain accidental; nevertheless, the possibility exists that it is a further disorder of amino acid metabolism associated with neuropathy.
\end{abstract}

\begin{tabular}{ll}
\hline KARGER & ( ) 1999 S. Karger AG, Basel \\
Fax +41 61306 12 34 & 1011-7571/99/0081-0073\$17.50/0 \\
$\begin{array}{l}\text { E-Mail karger@karger.ch } \\
\text { www.karger.com }\end{array}$ & Accessible online at: \\
& http://BioMedNet.com/karger
\end{tabular}

\section{Introduction}

Alcaptonuria is a rare autosomal recessive disorder of tyrosine characterized by lack of homogentisic acid oxidase, and the presence of homogentisic acid in the urine causing a characteristic dark colour when alkalinized or oxidized [1]. Alcaptonuria is associated with ochronosis or deposition of a black-brown pigment in the connective tissues, particularly in the cartilaginous joint surfaces, intervertebral discs, ear cartilage, ribs, skin, etc. The most common clinical manifestations include ochronotic arthritis affecting primary large weight-bearing joints, i.e. hips, knees and spine, pigmentation of the cartilage and occasionally cardiovascular ochronosis $[2,3]$.

Myelopathy caused by compression in alcaptonuria affection of the spine has been reported only in few patients [4-6]. So far, there have been no reports on peripheral neuropathy in alcaptonuria. Here, we report a 55year-old man who presented with myelopathy and neuropathy after an injury to the leg in a road accident. Radiological changes in the
Dr. M. Mavra, MD, MSc, PhD

Department of Neurology

Southend Hospital, Prittlewell Chase

Westcliff-on Sea, Essex SS0 ORY (UK) 


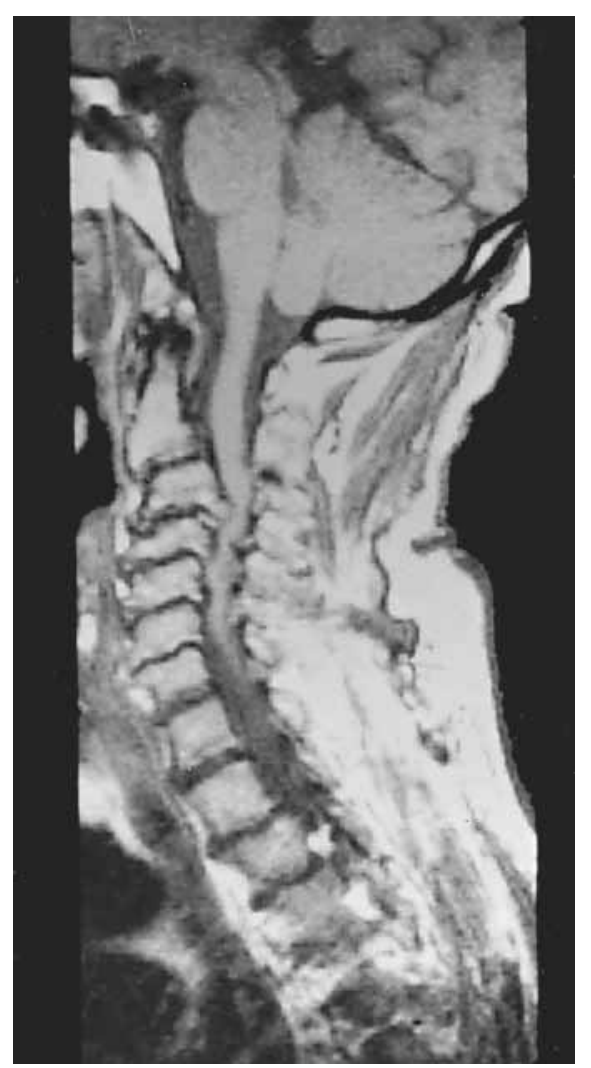

Fig. 1. MRI of the lateral cervical spine shows spondylotic changes and osteophytes, prominent at $\mathrm{C} 3 / \mathrm{C} 4$ level with significant spinal cord compression.

spine, hips and knees suggested the diagnosis of alcaptonuria, which was confirmed by clinical and laboratory findings.

\section{Case Report}

A 55-year-old Egyptian man who had numbness and tingling in both arms and legs, low back pain and pain in the right hip and both knees was admitted to the Mubarak Al-Kabeer Hospital in Kuwait. He was a healthy man until 6 months before, when he was injured in a traffic accident and sustained fracture to the right femur for which internal fixation was performed. No complications followed surgery but he kept complaining of persistent pain in his spine, knees and hips and could not walk except for a few steps supported by crutches. He also complained of numbness in both hands and feet. There was no family history of consanguinity or alcaptonuria.

On physical examination, the patient was seen to be of a short stature with a very short neck, and otherwise normal physically. There was darkening of both ears with irregular noduli in ear cartilages. The right leg was $2 \mathrm{~cm}$ shorter than the left leg. The patient's mental state was normal. There was mild weakness in both the arms and legs on either sides, with more in the hands and feet (MRS score 4/5). He had mild spasticity in the legs, absent tendon reflexes in the arms and legs, and extensor plantar responses on both legs. Sensation was diminished for touch and pinprick in both hands and feet in a glove and stocking distribution, and vibration sense was diminished in both feet and ankles. There was also diminished sensation for touch and pinprick in the distribution of the eight cervical and first dorsal nerve root dermatomes in the left arm.

Radiographs of the right hip showed narrowing of the joint space mainly in the outer half of the joint. Subarticular cysts and sclerosis were seen in the subchondral areas. In the left knee joint, calcifications in the intra-articular menisci and suprapatellar bursa were seen with multiple loose bodies in the space. Radiographs of the dorsolumbar spine showed narrowing of intervertebral disc spaces and waferlike calcifications of the discs. Marginal sclerosis of vertebral bodies and osteophytes were also present.

MRI of the lateral cervical spine showed advanced spondylotic changes and osteophytes, prominent at the $\mathrm{C} 3 / \mathrm{C} 4$ level with significant spinal cord compression (fig. 1). Similar moderate changes were seen at the levels $\mathrm{C} 4 / 5, \mathrm{C} 5 / 6$ and $\mathrm{C} 6 / 7$. There was anterior sliding of $\mathrm{C} 2$ and $\mathrm{C} 3$. MRI of the lateral dorsolumbar spine showed spondylotic changes, osteophytes, narrowing of disc spaces and fusion of D10/D11 and L3/L4 vertebral bodies.

Haematological and biochemical studies of the blood, including FBC, differential count, ESR, sugar, urea, creatinin, bilirubin, transaminases, electrolytes, glucose, lipids, and cholesterol, were all normal. Serum levels of vitamin $B_{12}$ and folates, vitamin $\mathrm{D}_{3}$, parathormone, and calcitonin and thyroid hormone were also normal. Immunology screen was normal. Paraproteins were not found in the blood and urine. Fresh urine was normal in colour, and became dark after it stood for $12 \mathrm{~h}$. Testing for abnormal metabolites turned out to be positive for homogentisic acid, as urine became brown when alkaline copper nitrate was added, and black colouration was seen when silver nitrate was added. 
Motor and sensory nerve conduction velocities were slightly reduced in the legs: 37 and $40 \mathrm{~m} / \mathrm{s}$ for the left and right peroneal nerves, respectively, and 37 and $42 \mathrm{~m} / \mathrm{s}$ for the right and left sural nerves, respectively. Terminal latencies were normal, and amplitudes were low: 1 and $0.2 \mathrm{mV}$ for the peroneal and tibial nerves, respectively, and $0.05 \mathrm{mV}$ for the sural nerve. There was no evidence of conduction block. Needle EMG was consistent with chronic neurogenic changes in the muscles innervated by C8/D1 nerve roots on the left side.

Muscle biopsy of the sural nerve (investigated at the Institute of Neurology in London) reported features of a very mild axonal neuropathy with no distinguishing features.

Neurosurgical management of the patient's myelopathy was considered, but the patient refused surgery, and was discharged on mild analgesics and physiotherapy. The patient left for Egypt and was lost for follow-up

\section{Discussion}

The metabolic, urinary and external manifestations are not serious components of alcaptonuria. It is only the lifelong, progressive pathological changes in the connective tissues leading to ochronotic arthritis that are serious consequences of the disorder [7]. A typical finding in the medical histories of alcaptonuric patients is the slow, relentless development of arthritic symptoms. They suffer chronically and have considerable pain in the hips, spine, knees and shoulders. The patients may be bedridden or severely crippled by the time they are 40 years or reach their early fifties.

The alcaptonuria in our patient had some unusual clinical features. Firstly, he had no known chronic symptoms prior to the injury to his leg when he developed severe disability. The diagnosis of ochronotic arthropathy was suggested by the characteristic degenerative changes on radiographs of the spine, hips and knees. Testing of the urine for pathologic metabolites and detection of homogentisic acid in the urine confirmed the diagnosis of the condition. Secondly, apart from arthritic pain which was the patient's major complaint, his disability was also caused by neurological impairment, both of the peripheral and the central nervous system. He had myelopathy due to compression of the spinal cord by osteophytes detected by MRI throughout the cervical spine, most prominent at the level of the C3/4 segment. Only few cases of myelopathy due to alcaptonuric involvement of the spine $[4,5]$ and pathologic fracture of vertebral bodies [6] have been reported. Fracture of an ankylosed ochronotic spine after trauma and consequent compression of the spinal cord was also reported in alcaptonuria [8].

The third unusual clinical manifestation in this case was axonal peripheral neuropathy evidenced by clinical and neurophysiological findings. None of the laboratory tests showed the presence of the treatable causes of neuropathy. We considered the underlying metabolic defect and the same mechanisms operating in the development of ochronotic arthritis as a possibility in the development of neuropathy in this patient. Mechanistic explanation for ochronotic arthritis has not been worked out, but it is clear that accumulation of homogentisic acid in the connective tissues directly or indirectly leads to arthritic changes. So far, there have been no reports on peripheral neuropathy in alcaptonuria. The association of alcaptonuria and peripheral neuropathy may remain accidental; nevertheless, the possibility exists that it is a further disorder of amino acid metabolism associated with neuropathy.

\section{Acknowledgement}

We would like to thank Mrs. Augustilia G. Pinto for her help in preparing the manuscript. 


\section{References}

1 Pollack MR, Chou YH, Cerda JJ, Steinman B, La Du BN, Seidman JG, Seidman CE: Homozygosity mapping of the gene for alkaptonuria to chromosome $3 \mathrm{q} 2$. Nat Genet 1993;5:201-204.

2 La Du BN Jr: Alcaptonuria and ochronotic arthritis. MD1 Biol Med 1991;8:31-38.

3 Kenny D, Ptacin MJ, Bamrah VS, Almagro U: Cardiovascular ochronosis: A case report and review of the medical literature. Cardiology 1990;77:477-483.
4 Kusakabe N, Tsuzuki N, Sonada M: Compression of the cervical cord due to alcaptonuric arthropathy of the atlanto-axial joint: A case report. J Bone Joint Surg Am 1995;77:274277.

5 Sharma RR, Ravi R, Bhama BA, Mathad NV, Mazarelo TB, Vaidya MM, Joshi DN: Cervico-medullary compression secondary to ochronotic arthritis affecting cranio-vertebral joints syndesmo-dental ochronotic arthritis. J Postgrad Med 1988;34: 253-257.
6 Marsile C, Menozzi C, Menozzi C: Un raro caso di compressione radicolo-midollare dorsale alta in soggetto con arthropatia ocronotica: Osservazioni clinicoradiologiche. Minerva Med 1995;86:61.

7 Van Offel JF, De Clerck LS, Francx LM, Stevens NVJ: The clinical manifestations of ochronosis: A review. Acta Clin Belg 1995;50:358-362.

8 Millea TP, Segal LS, Liss RG, Stauffer ES: Spine fracture in ochronosis. Clin Orthop 1992;281:208-211.

\section{Erratum}

In the article 'Bovine Spongiform Encephalopathy (BSE)-Mad Cow Disease' by Peter N. Campbell [Med Principles Pract 1998;7:172-186] the legend to figure 5 on p. 181 should read: 'Models for the tertiary structure of $\mathrm{PrP}^{\mathrm{c}}$ at the top and $\mathrm{PrP}^{\mathrm{Sc}}$ at the bottom. After Mestel [25]. 